Article

\title{
Dementia literacy in Greater Bay Area, China: Identifying the at-risk population and the preferred mass media for receiving dementia information
}

\author{
Angela Y. M. Leung ${ }^{*}$, Alex Molassiotis ${ }^{2}$, June Zhang ${ }^{3}$, Renli Deng', Ming Liu ${ }^{5}$, Iat Kio Van ${ }^{6}$, \\ Cindy Siu U Leong ${ }^{7}$, Isaac S.H. Leung ${ }^{8}$, Doris Y.P. Leung ${ }^{9}$, Xiaoling Lin ${ }^{10}$, Alice Y Loke ${ }^{11}$
}

1 School of Nursing, The Hong Kong Polytechnic University, Hong Kong, China; Centre for Geronotological Nursing (CGN), School of Nursing, The Hong Kong Polytechnic University, Hong Kong, China; angela.ym.leung@polyu.edu.hk

2 School of Nursing, The Hong Kong Polytechnic University, Hong Kong, China; World Health Organization Collaborating Centre for Community Health Services, The Hong Kong Polytechnic University, Hong

Kong, China; alex.molasiotis@polyu.edu.hk

3 School of Nursing, Sun Yat-sen University, Guangzhou, China; zhangje@mail.sysu.edu.cn

4 The $5^{\text {th }}$ Affiliated Hospital of Zhuyi Medical University, Zhuhai, China; 690891192@qq.com

5 Macao Polytechnic Institute, Macau, China; karryliu@ipm.edu.mo

6 Kiang Wu Nursing College of Macau, Macau, China; van@kwnc.edu.mo

7 Macao Polytechnic Institute, Macau, China; suleong@ipm.edu.mo

8 Centre for Geronotological Nursing (CGN), School of Nursing, The Hong Kong Polytechnic University, Hong Kong, China; Department of Statistics, The Chinese University of Hong Kong; isaacleung201709@gmail.com

9 School of Nursing, The Hong Kong Polytechnic University, Hong Kong, China; doris.yp.leung@polyu.edu.hk

10 School of Nursing, Sun Yat-sen University, Guangzhou, China; linxling3@mail.sysu.edu.cn

11 School of Nursing, The Hong Kong Polytechnic University, Hong Kong, China; alice.yuen.loke@polyu.edu.hk

* Correspondence: Dr. Angela Y.M. Leung: angela.ym.leung@polyu.edu.hk; Tel.: +852-2766-5587

\begin{abstract}
Background: This study aimed to assess the dementia literacy (DL) level of communitydwelling adults in the four cities (Hong Kong, Guangzhou, Macau and Zhuhai) of the Greater Bay Area of China and to determine the preferred mass media for receiving dementia information. Methods: A multi-city cross-sectional study with 788 community-dwelling adults completed the survey. Dementia literacy was indirectly measured by two validated scales, 30-item Alzhiemer's Disease Knowledge Scale (ADKS) and 20-item Dementia Attitudes Scale (DAS). When the ADKS total score was $<15$ and DAS total score was $<70$, it was considered as 'inadequate dementia literacy'. Participants were also asked to indicate whether they would like to receive dementia information via digital media or traditional media. Chi-square tests and logistic regressions were undertaken. Results: About one-third of the participants had inadequate dementia literacy. Those with young age or secondary education preferred to get dementia information from social media. But people living in public housing would like to get information from government or hospital websites. Middle-aged participants inclined to learn dementia from television or radio. Conclusion: It is worthy to conduct territory-wide public education in dementia and develop strategies according to their preferences in the types of mass media.
\end{abstract}

Keywords: health literacy; dementia; cross-sectional study; community; Alzheimer's Disease; knowledge 


\section{Introduction}

Dementia is a growing health concerns in many countries including China. In 2016, there were 46.8 million people live with dementia in the globe and about $25 \%$ of them reside in China [1]. A recent meta-analysis of 96 studies showed that the pooled prevalence of dementia was $5.3 \%$ and $7.2 \%$ in Mainland China and Hong Kong respectively [2]. As the number of people suffering from dementia increases, an increasing attention has been paid to dementia literacy of the public. Greater Bay Area is the newly developed integrated economic and business zone in China, where 69 million people are living. It consists of seven cities (such as Guangzhou, Zhuhai) and two special administrative regions (Hong Kong and Macau). In line with the growth of economic activities in this area, the local governments have been spending substantial amount of money in health care systems to keep the citizens healthy. Both Hong Kong and Macau have their own health care systems which are different from Guangzhou and Zhuhai. Hong Kong's gross domestic product (GDP) is the highest (U\$319 billion), its dependency rate is the lowest $(22.2 \%)$, the prevalence of dementia is the highest in the region (see the supplementary material). It is estimated that there are 9.55 million persons with dementia in China and Hong Kong[2]. As the population of this area is aging, much attention has been given to the recognition of dementia in the last decade. Dementia literacy becomes one of the most discussed issues in the Greater Bay Area.

Dementia literacy refers to knowledge of dementia and attitudes towards persons with dementia [3]. With inadequate dementia literacy, individuals may not be able to have enough knowledge to recognize the symptoms of dementia, identify treatment options, provide essential care and supports to the persons with dementia [4]. In addition, individuals with inadequate dementia literacy would feel tremendous discomfort when the persons with dementia are around them, or would not feel obliged to support the patients and their caregivers [4]. Social comfort to dementia was found to be prevalent but this phenomenon could be reverted through education by increasing knowledge of dementia [5]. By now, most of the studies in dementia literacy were from high-income countries such as Low and team's study [3,6] in Australia and Woo's study [7] in USA. There was a sparsity of studies from low- and middle-income countries [8], and China is one of these countries with fast growing prevalence of dementia and therefore dementia literacy becomes an important topic for discussion. To the best knowledge of the project team, three studies in relation to dementia literacy were identified. A survey with 140 participants in Tianjin, China showed that only $16 \%$ of the participants knew the risk factors of dementia and $56 \%$ of the participants were not sure whether they should share the diagnosis of dementia with the patients [9]. Another study indicated that majority of the respondents (77\%) had personal fear of developing Alzheimer's Disease (AD) and being female, those with poor self-rated health, high proximity to AD and high perceived severity of AD were more likely to indicate such fear [10]. A recent study investigated the dementia literacy of older adults (aged 60 or above) living in 34 urban cities in China and found that their dementia literacy was very low [11]. The studies mentioned above had investigated the Chinese participants' basic knowledge about dementia, their intended actions if their own relatives suffered from dementia, their personal fear of developing dementia, and dementia literacy level of older adults. Obviously, there is still a knowledge gap: How many community-dwelling adults have inadequate dementia literacy? Who are the at-risk group with inadequate dementia literacy?

Mass media plays an important role in health promotion. Evidence has showed that mass media promotes healthy behaviors (such as safe sex, skin cancer prevention) through descriptive norms [12]. Nonetheless, the role of mass media in dementia education has seldom been investigated. Would traditional mass media still be the best choice for promoting dementia literacy? Would digital media become the favorable channels for receiving information about dementia? Knowing the preferred channels would help to develop appropriate strategies for disseminating relevant health information to the public.This study aimed to assess dementia literacy level of community-dwelling adults in the four cities (Hong Kong, Guangzhou, Macau and Zhuhai) of the Greater Bay Area of China, and the preferred types of mass media for receiving dementia information. 


\section{Materials and Methods}

\subsection{Design, Data Collection and Participants}

This is a multi-city cross-sectional study with the samples representing respective population ratio in the selected cities/regions and targeting to recruit 200 subjects in each city. A convenience sample was used in this study. The study population were adults aged 18 or above, cognitively intact (Short Portable Mental Status Questionnaire, SPMSQ >7), able to read Chinese, and had lived in the respective city for at least 1 year. Those who were being hospitalized, living in residential care homes were excluded. In this study, we only included respondents aged 18-64 in the analysis. University students in different cities were trained to be data collectors. They approached as many as people they could in community centres or public places (such as bus-stops, parks, shopping malls, markets), screened for their eligibility, obtained written consents, and provided assistance to those who needed in completing the questionnaires. Data collection was conducted from July 2017 to May 2018 in the four cities.

\subsection{Measures}

Outcome measure was dementia literacy. Since there was no single validated instrument for measuring dementia literacy, we measured the variable indirectly by mapping the two most relevant concepts - knowledge about dementia and attitudes towards dementia, as suggested by Low \& Anstey [3].

Knowledge about dementia was measured by Alzheimer's Disease Knowledge Scale (ADKS): The ADKS contains 30 true/false questions that assess knowledge related to AD assessment, diagnosis, caregiving, life impact, prevalence, prevention, risk factors, symptoms, treatment and management [13]. A composite score was calculated by counting the number of questions answered correctly, and the score can range from 0 to 30. The ADKS has been shown to have good internal consistency (alpha $=0.71)$, adequate test-retest reliability (reliability coefficient $=0.81, p<0.001)$ [13].

Attitudes towards dementia was measured by Dementia Attitudes Scale (DAS): it is a 20-item instrument. Each item is rated on a 7-point Likert scale ranging from 1 (strongly disagree) to 7 (strongly agree), and the total score of the scale could be from 20 to 140. The higher the total score is, the more positive the attitude toward dementia. The result of confirmatory factor analysis (CFI $=0.95$, RMSEA $=0.06, C F I=0.87$ ) indicated that DAS has a reasonably good fit model. Cronbach's alpha of this scale is 0.83 [14].

Then, we created the variable - inadequate dementia literacy if ADKS total score $<15$ and DAS total score $<70$.

Another outcome measure was the channels for receiving dementia information. Participants were asked to indicate their preferred types of mass media to receive relevant information about dementia, and they could choose more than one type. A total of 12 options were given. The options were then categorized into four types: social media, websites, paper-based materials, television/radio. Social media included WhatsApp, Facebook, QQ, Instagram, Baidu, WeChat, and Blog, while websites referred to websites from government units, hospitals, health-related organizations and non-government organizations. Paper-based materials referred to posters, newspapers, magazines and books.

\subsection{Ethical Statement}

Written consent was obtained from the eligible subjects before the completion of the questionnaires. Ethical approval to conduct the study was obtained from the Human Subject Ethics Subcommittee of Sun-Yat Sen University, the Hong Kong Polytechnic University (HSEARS20170511002), Kiang Wu Hospital College of Nursing of Macau, and the Zhuyi University of Zhuhai.

\subsection{Statistical Analysis}

Descriptive statistics, including numbers, percentages, means and standard deviation, were performed on demographics, dementia literacy, ADKS total score, and DAS total score. Logistic 
regression models with backward elimination were used to identify associated demographic factors with inadequate dementia literacy in each city/region separately. Another set of four logistic regression models were conducted to identify associated factors of participants in favoring of a particular type of mass media for receiving dementia information. All statistical analyses were performed using SPSS version 23.0. The level of significance was set at $\mathrm{p}<0.05$.

\section{Results}

\subsection{Demographics and level of dementia literacy}

A total of 844 people completed the survey. Among these, 788 community-dwelling adults (aged 64 or below) were included in the analysis, with 242 from Hong Kong (HK), 184 from Guangzhou (GZ), 178 from Macau (MA) and 184 from Zhuhai (ZH).

Table 1 showed the demographics of the participants. Majority of the participants were employed. About half of participants were married in Hong Kong, Guangzhou and Macau, but significantly more participants were married in Zhuhai. In terms of education level, Hong Kong has the highest percentage of participants possessing university level among the four cities/regions. About half of the participants were living in private housing in Hong Kong, Guangzhou and Zhuhai.

Zhuhai had the highest percentage of the participants with inadequate dementia literacy $(50.0 \%)$ and the percentage was significantly higher than the other three cities/regions (HK: $31.4 \%$; GZ: $32.6 \%$; MA: $34.8 \%, p<0.001$ ). Looking into the two components of dementia literacy (knowledge and attitudes), Zhuhai also has the highest percentage of participants with low dementia knowledge score (ADKS < 15) (HK: 25.2\%; GZ: 25.5\%; MA: 29.2\%; ZH: 38.0\%; $\mathrm{p}<0.05$ ) and poor attitudes towards dementia (DAS < 70) (HK: 8.3\%; GZ: 9.2\%; MA: 8.4\%; ZH: 20.1\%, p<0.001).

Table 1. Demographics of the participants by city

\begin{tabular}{|c|c|c|c|c|c|c|c|c|}
\hline & \multicolumn{2}{|c|}{ Hong Kong } & \multicolumn{2}{|c|}{ Guangzhou } & \multicolumn{2}{|l|}{ Macau } & \multicolumn{2}{|l|}{ Zhuhai } \\
\hline & Count & $\%$ & Count & $\%$ & Count & $\%$ & Count & $\%$ \\
\hline \multicolumn{9}{|l|}{ Age } \\
\hline $0-44$ & 128 & $52.9 \%$ & 126 & $68.5 \%$ & 110 & $61.8 \%$ & 106 & $57.6 \%$ \\
\hline $45-64$ & 114 & $47.1 \%$ & 58 & $31.5 \%$ & 68 & $38.2 \%$ & 78 & $42.4 \%$ \\
\hline \multicolumn{9}{|l|}{ Gender } \\
\hline Female & 136 & $56.2 \%$ & 93 & $50.5 \%$ & 96 & $53.9 \%$ & 92 & $50.0 \%$ \\
\hline Male & 106 & $43.8 \%$ & 91 & $49.5 \%$ & 82 & $46.1 \%$ & 92 & $50.0 \%$ \\
\hline \multicolumn{9}{|l|}{ Education } \\
\hline$<=$ Primary level & 24 & $9.9 \%$ & 9 & $4.9 \%$ & 22 & $12.4 \%$ & 27 & $14.7 \%$ \\
\hline Secondary level & 94 & $38.8 \%$ & 92 & $50.0 \%$ & 86 & $48.3 \%$ & 134 & $72.8 \%$ \\
\hline Tertiary level & 124 & $51.2 \%$ & 83 & $45.1 \%$ & 70 & $39.3 \%$ & 23 & $12.5 \%$ \\
\hline \multicolumn{9}{|l|}{ Marital status } \\
\hline Singled/Others & 128 & $52.9 \%$ & 90 & $48.9 \%$ & 82 & $46.1 \%$ & 67 & $36.4 \%$ \\
\hline Married & 114 & $47.1 \%$ & 94 & $51.1 \%$ & 96 & $53.9 \%$ & 117 & $63.6 \%$ \\
\hline \multicolumn{9}{|l|}{ Employment status } \\
\hline Employed & 167 & $69.0 \%$ & 104 & $56.5 \%$ & 121 & $68.0 \%$ & 126 & $68.5 \%$ \\
\hline Unemployed & 35 & $14.5 \%$ & 26 & $14.1 \%$ & 46 & $25.8 \%$ & 40 & $21.7 \%$ \\
\hline Student & 40 & $16.5 \%$ & 54 & $29.3 \%$ & 11 & $6.2 \%$ & 18 & $9.8 \%$ \\
\hline \multicolumn{9}{|l|}{ Accommodation } \\
\hline Private & 117 & $48.3 \%$ & 95 & $51.6 \%$ & 124 & $69.7 \%$ & 104 & $56.5 \%$ \\
\hline Public & 92 & $38.0 \%$ & 20 & $10.9 \%$ & 20 & $11.2 \%$ & 4 & $2.2 \%$ \\
\hline
\end{tabular}


Others 33 $13.6 \%$ 69 $37.5 \% \quad 34$ $19.1 \% \quad 76$ $41.3 \%$

\subsection{Profiles of participants with inadequate dementia literacy by city}

We identified the at-risk population with inadequate dementia literacy. Results of the regression models showed that in Hong Kong, those with lower educational level (primary education: OR 6.219, $\mathrm{p}<0.01$; secondary education: $1.891, \mathrm{p}=0.162$; tertiary education: reference), being unemployed (OR 5.257, $\mathrm{p}<0.01$; employed: OR 4.066, $\mathrm{p}=0.053$; student: reference) were more likely to have inadequate dementia literacy than their counterparts. Education was also a significant factor associated with inadequate dementia literacy in Guangzhou: those with low education were more likely to have inadquate dementia literacy (primary education: OR 2.274, $\mathrm{p}<0.05$; secondary education: $0.806, \mathrm{p}=$ 0.799; tertiary education: reference). Another factor 'housing' associated with dementia literacy was noted in Guangzhou: those who were living in private housing (OR 1; living in public housing: OR 0.126, $\mathrm{p}<0.05$ ) were the at-risk population with inadequate dementia literacy. On the other hand, marrital status also associated with dementia literacy in Zhuhai: married people (OR 2.486 p<0.01) were more likely to have inadequate dementia literacy than those who were single.

\subsection{Preference of mass media}

Among the four types of media, websites were the only type preferred by the participants regardless of the locations (Table 2). Those participants with tertiary education (OR 1) and secondary education (OR 1.035), had adequate demential literacy (OR 1; inadequate: $0.728, p<0.05$ ), and lived in public housing (OR 1.518, $\mathrm{p}<0.05$ ) were more likely to prefer getting dementia information from government or hospital websites (Table 3). On the contrary, social media, the other digital media, was more likely to be preferred by those who had secondary education (OR 1.590, p<0.05) but less likely preferred by those who were older (OR 0.951, $\mathrm{p}<0.001$ ). It is worthy to note that participants from Guangzhou (OR 3.150, p<0.001) and Zhuhai (OR 3.712, p<0.001) were more likely to use social media to receive dementia information than Hong Kong participants.

Table 2. Preference of mass media for receiving dementia information by city

\begin{tabular}{|c|c|c|c|c|c|c|c|c|c|c|}
\hline & \multicolumn{2}{|c|}{ Hong Kong } & \multicolumn{2}{|c|}{ Guangzhou } & \multicolumn{2}{|c|}{ Macau } & \multicolumn{2}{|c|}{ Zhuhai } & \multirow[t]{2}{*}{$\chi^{2}$} & \multirow[t]{2}{*}{$\mathrm{p}$-value } \\
\hline & $\mathrm{n}$ & $\%$ & $\mathrm{n}$ & $\%$ & $\mathrm{n}$ & $\%$ & $\mathrm{n}$ & $\%$ & & \\
\hline Social media & 82 & $33.88 \%$ & 125 & $67.93 \%$ & 83 & $46.63 \%$ & 115 & $62.50 \%$ & 60.56 & $<0.001$ \\
\hline Websites & 134 & $55.40 \%$ & 92 & $50.00 \%$ & 103 & $57.90 \%$ & 87 & $47.30 \%$ & 5.30 & 0.151 \\
\hline Paper-based & 112 & $46.30 \%$ & 48 & $26.10 \%$ & 108 & $60.70 \%$ & 56 & $30.40 \%$ & 56.63 & $<0.001$ \\
\hline TV/radio & 168 & $69.40 \%$ & 93 & $50.50 \%$ & 101 & $56.70 \%$ & 129 & $70.10 \%$ & 23.17 & $<0.001$ \\
\hline
\end{tabular}

Table 3. Preferred digital media for receiving dementia information

\begin{tabular}{clll}
\hline \multicolumn{3}{c}{ Social media } & \\
\hline \multicolumn{1}{l}{ Age } & Odds Ratio & $95 \%$ CI & \\
$18-44$ & Ref & & $<0.001$ \\
$45-64$ & 0.951 & $0.937,0.966$ & \\
Education & & & \\
Tertiary & Ref & & 0.019 \\
Secondary & 1.590 & $1.079,2.345$ & 0.721 \\
Primary & 0.887 & $0.459,1.713$ &
\end{tabular}


Cities

\begin{tabular}{|c|c|c|c|}
\hline Hong Kong & Ref & & \\
\hline Guangzhou & 3.150 & $2.011,4.933$ & $<0.001$ \\
\hline Macau & 1.884 & $1.232,2.882$ & 0.003 \\
\hline Zhuhai & 3.712 & $2.413,5.711$ & $<0.001$ \\
\hline Constant & 1.978 & & 0.014 \\
\hline \multirow[t]{2}{*}{ Negelkerke R2 } & & 0.22 & \\
\hline & Websi & & \\
\hline \multicolumn{4}{|l|}{ Education } \\
\hline Tertiary & Ref & & \\
\hline Secondary & 1.035 & $0.746,1.435$ & 0.838 \\
\hline Primary & 0.465 & $0.269,0.804$ & 0.006 \\
\hline \multicolumn{4}{|l|}{ Accommodation } \\
\hline Private & Ref & & \\
\hline Public & 1.518 & $1.031,2.234$ & 0.035 \\
\hline \multicolumn{4}{|l|}{ Dementia literacy } \\
\hline Adequate & Ref & & \\
\hline Inadequate & 0.728 & $0.538,0.984$ & 0.039 \\
\hline Constant & 1.076 & & 0.711 \\
\hline Negelkerke R2 & & 0.06 & \\
\hline
\end{tabular}

Note. Social media included Facebook, QQ, Instagram, Baidu, WeChat, and Blog, while websites referred to websites from government units, hospitals, health-related organizations and non-government organizations.

We also investigated the preference of traditional media for health promotion - paper-based materials and TV/radio. Middle-aged participants (OR 1.013, p<0.05) and, compared to Hong Kong participants, Macau participants (OR 1.747, p<0.01) were more likely to while Guangzhou and Zhuhai participants were less likely to prefer to use paper-baed materials to get dementia information (Table 4). For receiving dementia information from TV or radio, older participants were more likely but Macau (OR 0.530 p $<0.01$ ) and Zhuhai (OR 0.463 p $<0.001$ ) as compared to Hong Kong participants were less likely to prefer this type of media channel.

Table 4. Preferred traditional media for receiving dementia information

\begin{tabular}{clll}
\hline \multicolumn{4}{c}{ Paper-based materials } \\
\hline \multicolumn{1}{c}{ Odds Ratio } & $95 \%$ CI & \\
\hline Age & Ref & & \\
$18-44$ & 1.013 & $1.003,1.024$ & 0.013 \\
$45-64$ & & & \\
Cities & Ref & & \\
Hong Kong & 0.506 & $0.337,0.758$ & 0.001 \\
Guangzhou & 1.747 & $1.177,2.592$ & 0.006 \\
Macau & 0.434 & $0.286,0.660$ & $<0.001$ \\
Zhuhai & 0.513 & & 0.007 \\
\hline Constant & & 0.11 & \\
Negelkerke R ${ }^{2}$ & & & \\
\hline
\end{tabular}




\section{Television / radio}

\begin{tabular}{llll}
\hline Age & & & \\
$18-44$ & Ref & $1.006,1.033$ & 0.004 \\
$45-64$ & 1.019 & & \\
Cities & & & \\
Hong Kong & Ref & $0.666,1.560$ & 0.928 \\
Guangzhou & 1.020 & $0.350,0.803$ & 0.003 \\
Macau & 0.530 & $0.308,0.696$ & $<0.001$ \\
Zhuhai & 0.463 & & 0.284 \\
\hline Constant & 1.338 & 0.08 & \\
Negelkerke $\mathrm{R}^{2}$ & & & \\
\hline
\end{tabular}

Note. Paper-based materials referred to posters, newspapers, magazines and books.

\section{Discussion}

This is the first study assessing the level of dementia literacy in the Greater Bay Area of China. About one-third to half of the participants in this area of China had inadequate dementia literacy. This finding echoed those of studies in developed countries such as Australia [6], Cambodia, Fiji and the Philippines [15], showing inadequate dementia literacy was prevalent in general. This study has filled the missing piece of puzzle in dementia literacy in China by providing further evidence of inadequate dementia literacy in community-dwelling adults (aged 18-64) in addition old adults (aged 65 or above) in China [11]. Public education to improve citizens' knowledge about dementia (which include the understanding of dementia symptoms, treatment options, care needs, and prognosis) and cultivate their positive attitudes towards dementia should be extensively supported. The Hong Kong SAR Government has already placed dementia public education as part of its mental health policy, highlighting the strategy of bringing together education, housing, police, health care, social care authorities and research institutions to co-create dementia-friendly community [16]. For example, in education settings, school curriculum will be modified to include lifestyle modification and its relationship with dementia. Training will be given to police force so that policemen can have better understanding of dementia symptoms and behaviors of persons with dementia. When necessary, police force will support the search of persons with dementia who may get lost or wander away from home. Such initiative is a good example of reference for increasing city-based awareness-raising efforts with the participation from people of different sectors.

We identified the vulnerable populations for inadequate dementia literacy in each of the four cities, and these findings could help to focus the resources to improve citizens' dementia literacy in individual cities/regions. As noted, those with low education were at risk of low dementia literacy. To educate these people, materials should be developed in consideration of readers' literacy. Using pictures or photos in the educational materials is recommended, especially those with lower educational level. Comic books have been found to be effective to improve knowledge about medication adherence, drugs storage and health literacy among Chinese people with low education level [15]. Fotonovelas (or comic books illustrated with photos) were shown to increase overall knowledge of dementia among Latino older adults even though their educational level was not high [17]. With these evidences, we could consider develop photo-based interventions or use comic books to promote dementia literacy.

Compared to the previous studies $[15,18]$ which considered age, gender, education, marital status, employment status, and per capita annual income as the risk factors of poor dementia literacy, the current study has identified another associated factor of inadequate dementia literacy, housing. Interestingly, this finding was only significant in Guangzhou but not in other three cities/regions. Housing and poverty are connected: in many occasions, living in public housing offers participants the opportunities to alleviate poverty because they pay less in rents [19]. For those who are financially 
capable, they are more likely to purchase their own houses and thus private housing is usually owned by middle class. Nonetheless, such common phenomenon does not seem to happen in Guangzhou. Reviewing the housing policy in Guangzhou, we note that those who are living in private housing may not be middle-class participants. This is probably related to the housing reform in Guangzhou in 1990s in which former danwei houses (originally these were government property) had been privatized at net cost price and the government largely involved in the pricing so as to ensure private housing is affordable to the hukou holders (that is, citizens entitled for permanent residency in Guangzhou) [20]. As a result, individual property purchase is unusually high in Guangzhou [20]. Common areas in housing estates could be the ideal platforms for promoting dementia literacy.

Using social media to deliver public education in dementia was one of the strategies favoured by the participants, particularly the young generation, in the current study. Such proposal is worthy to be supported, as social media has already been embedded in daily life and it is a novel medium for the dissemination of public health information [21]. Nonetheless, by now, limited empirical studies have been carried out to promote dementia using social media. One of the two studies that could be retrieved was qualitative study involving 42 adolescents aged 12-18 in United Kingdom, discussing the key features of an effective dementia education [22]. These adolescents proposed to use Facebook, Instagram and YouTube to facilitate and modernize their learning about dementia [22]. The findings of the current study seemed to echo this recommendation, acknowledging the agreement of using social media to conduct public education in dementia, but our findings extend the target population to those aged 18-44. This implies that using social media to improve people's dementia literacy could be extended to middle-aged adults. Another pilot study explored the use of YouTube to deliver dementia education to older adults aged 55 or above and found that more participants (aged 65 or above) had used YouTube to learn dementia in the $2^{\text {nd }}$ year than in the $1^{\text {st }}$ year [23]. Thus, different types of social media have huge potential to deliver quality dementia education to the public. WeChat, Baidu, QQ are the frequently used social media in Guangzhou and Zhuhai, on the contrary, WhatsApp, Facebook and YouTube are common in Hong Kong and Macau, and these platforms were chosen by the participants of this study. Further investigation is warranted to determine how these social media platforms could be used in dementia education in the Chinese population. In Hong Kong, a pilot test of the use of Facebook to improve health care professionals' dementia literacy has been carried out and it was found to be feasible and welcomed by the participants [24, 25]. There is a possibility of extending this work to the general public in Chinese population. No matter which types of social media is used, ethical issues such as protecting privacy and confidentiality should be considered [26].

Improving dementia literacy requires the use of multiple channels and techniques [7]. Traditional mass media such as television and radio were considered as the preferred channels to get dementia information in Guangzhou and Hong Kong. These channels could reach a large audience in a short period of time, nonetheless, no study has investigated the impacts of television and radio episodes on the change of dementia literacy. Future research in this particular area is warrant.

This study had several limitations. Firstly, the use of a cross-sectional design limited the extent to which causal inferences of the observed associations could be established, and the findings should be further examined in longitudinal studies to establish the temporal validity of any associations found. Second, some of the important factors, such as personal experience in dementia care or impact of Chinese culture on dementia, were not measured and hence precluded us from examining their independent and potential interaction effects on dementia literacy and the preferred type of media to receive dementia information. This could also partly explain the limited explanatory power of the associated factors for the outcome variables. Finally, the current sample was obtained using convenience sampling, which might not have produced representative samples of the population in the four cities which will limit the generalizability of the current findings to the larger population in the four cities. 


\section{Conclusions}

Since a significant portion of the population have inadequate dementia literacy in Greater Bay Area of China, it is worthy to conduct public education in dementia. Strategies which targeted for specific groups of citizens in each city could be formulated according to their preferences in different types of mass media. These recommendations respond to the World Health Organization's (WHO) Global Calls for Actions in which campaigns are developed and implemented to raise public awareness about dementia and foster dementia-inclusive societies by 2025 [27].

Author Contributions: Conceptualization, A.Y.M.L. and A.M.; methodology, A.Y.M.L, A.M., I.S.H.L. and D.Y.P.L.; formal analysis, A.Y.M.L, A.M., I.S.H.L. and D.Y.P.L.; investigation, A.Y.M.L, A.M., J.Z., R.D., M.L., D.Y.P.L., A.Y.L.; resources, J.Z., R.D., M.L., I.K.V., C.S.U.L., X.L. and A.Y.L.; data curation, A.Y.M.L, J.Z., R.D., M.L., I.K.V., C.S. U.L. and I.S.H.L.; writing - original draft preparation, A.Y.M.L., C.S.U.L., I.S.H.L. and D.Y.P.L., and X.L.; writing - review and editing, A.M., J.Z., R.D., M.L., I.K.V., A.Y.L.; supervision, J.Z., R.D., M.L., I.K.V., C.S.U.L., X.L. ; resources, J.Z., R.D., M.L., I.K.V., C.S.U.L., X.L.; project administration, X. L..; funding acquisition, A.M. and A.Y.L.

Funding: This project was funded by the Galaxy Entertainment Group Foundation.

Acknowledgments: We wish to acknowledge the invaluable contribution of the participants and volunteers (students from the Hong Kong Polytechnic University, Sun Yat-sen University, the $5^{\text {th }}$ Affiliated Hospital of Zhuyi Medical University, Macao Polytechnic Institute, and Kiang Wu Nursing College of Macau) who helped out in data collection. Special thanks go to Dr. Alice Tsang, Dr. Bernice Nogueira for their kind support and assistance during student training and participant recruitment. We would also like to thank the community centres/non-government organizations for their kind support in coordinating their members to join this survey. Without all the kind support from all the organizations, volunteers and participants, the implementation of this project would not be possible

Conflicts of Interest: The authors declare no conflict of interest. The funders had no role in the design of the study; in the collection, analyses, or interpretation of data; in the writing of the manuscript, or in the decision to publish the results.

\section{Appendix A}

Table A1 contains epidemiological data of the four cities of Greater Bay Area of China. This provides additional information to allow readers to understand the differences among the four cities. 
1 Table A1. Epidemiological data of the four cities of Greater Bay Area of China

\begin{tabular}{|c|c|c|c|c|c|c|}
\hline Cities & $\begin{array}{l}\text { Area \& } \\
\text { Population }\end{array}$ & $\begin{array}{l}\text { Gross Domestic } \\
\text { Product (GDP) }\end{array}$ & Literacy rate & $\begin{array}{l}\text { Dependency } \\
\text { Rate }\end{array}$ & Dementia prevalence & Dementia Cost \\
\hline Guangzhou & $\begin{array}{l}7,436 \mathrm{sq} \cdot \mathrm{km} \\
\text { Population } \\
14.04 \text { million }\end{array}$ & US $\$ 284.6$ billion & $\begin{array}{l}99.6 \% \\
\text { (Mainland } \\
\text { China) }\end{array}$ & Unknown & $0.5 \%(70,000)$ & $\begin{array}{l}\text { US\$ } 359.91 \text { per patient a month to } \\
\text { treat dementia }\end{array}$ \\
\hline $\begin{array}{l}\text { Hong } \\
\text { Kong }\end{array}$ & $\begin{array}{l}1,104 \text { sq.km } \\
\text { Population } \\
8.25 \text { million }\end{array}$ & US\$ 319.3 billion & $99 \%$ & $22.2 \%$ & $\begin{array}{l}5-8 \%(60-80 \mathrm{yrs}) \\
20-30 \%(80+\mathrm{yrs}) \\
1.7 \text { million (mid-2016) }\end{array}$ & $\begin{array}{l}\text { US } \$ 3.2 \text { billion } \\
\text { US } \$ 190 \text { million in medical } \\
\text { expenses } \\
\text { US } \$ 1.5 \text { billion in informal care }\end{array}$ \\
\hline Macau & $\begin{array}{l}29.2 \mathrm{sq} . \mathrm{km} \\
\text { Population } \\
0.64 \text { million }\end{array}$ & US $\$ 44.7$ billion & $96.2 \%$ & $30.3 \%$ & $0.6 \%(4,000$ people $)$ & No information \\
\hline Zhuhai & $\begin{array}{l}1,696 \text { sq.km } \\
\text { Population } \\
1.68 \text { million }\end{array}$ & US\$ 32.3 billion & $\begin{array}{l}99.6 \% \\
\text { (Mainland } \\
\text { China) }\end{array}$ & $27.3 \%$ & No information & No information \\
\hline
\end{tabular}




\section{References}

1. Alzheimer's Disease International. World Alzheimer Report 2018. Available online: https://www.alz.co.uk/research/world-report-2018 (accessed on 22 Dec 2019).

2. Wu, Y-T.; Ali, G-C.; Guerchet, M.; Prina, A.M.; Chan, K.Y.; Prince, M.; Brayne, C. Prevalence of dementia in mainland China, Hong Kong and Taiwan: an updated systematic review and meta-analysis. Int $J$ Epidemiol 2018, 47(3), 709-719. Doi: https://doi.org/10.1093/ije/dyy007

3. Low, L.F.; Anstey, K.J. Dementia literacy: recognition and beliefs on dementia of the Australian public. Alzheimers Dement 2009, 5(1), 43-49.

4. Leung, A.Y.M.; Lo, S.; Leung, I.; Liu, J.W.Y.; Ting, S. Improving health literacy and medication compliance through comic books: A quasi-experimental study in Chinese community-dwelling older adults. Glob Health Promot - Special issue in health literacy 2018, 25(4), 67-78. https://doi.org/10.1177/1757975918798364

5. Eber, A.R.; Kuliber, D.; McFadden, S.H. Effects of dementia knowledge and dementia fear on comfort with people having dementia: Implications for dementia-friendly communities. Dementia (London) 2019. First published online Feb 10, 2019. doi: 10.1177/1471301219827708.

6. Low, L.F.; Anstey, K.J;; Lackersteen, S.M.; Camit, M.; Harrison, F.; Draper, B.; Brodaty, H. Recognition, attitudes and causal beliefs regarding dementia in Italian, Greek and Chinese Australians. Dement Geriatr Cogn Disord 2010, 30(6), 499-508.

7. Woo, B.K.P. Dementia Literacy Issues in the Care of Chinese American Immigrants. Gerontol Geriatr Med 2019 Jan 29. doi: $10.1177 / 2333721419826005$.

8. Cations, M.; Radisic, G.; Crotty, M.; Laver, K.E. What does the general public understand about prevention and treatment of dementia? A systematic review of population-based surveys. PLoS ONE 2018, 13(4), e0196085.

9. Yang, H.F.; Cong, J.Y.; Zang, X.Y.; Jiang, N.; Zhao, Y. A study on knowledge, attitudes and health behaviours regarding Alzheimer's disease among community residents in Tianjin, China. J Psychiatr Ment HLT 2015, 22, 706-714.

10. Zeng, F.; Xie, W.T.; Wang, Y.J.; Luo, H.B.; Shi, X.Q.; Zou, H.Q.; Zeng, Y.Q.; Li, Y.F.; Zhang, S.R.; Lian, Y. General public perceptions and attitudes toward Alzheimer's disease from five cities in China. J. Alzheimer's Dis 2015, 43, 511-518.

11. Zhang, H.; Loi, S.M.; Zhou, S.; Zhao, M.; Lv, X.; Wang, J.; Wang, X.; Lautenschlager, N.; Yu, X.; Wang, H. Dementia literacy among community-dwelling older adults in urban China: A Cross-sectional study. Front Public Health 2017, 5, 124. doi: 10.3389/fpubh.2017.00124.

12. Hong, Y.; Kim, S. Influence of presumed media influence for health prevention: how mass media indirectly promote health prevention behaviors through descriptive norms. Health Commun 2019 Sep 9, 1-11. doi: 10.1080/10410236.2019.1663585.

13. Carpenter, B.D.; Balsis, S.; Otilingam, P.G.; Hanson, P.K.; Gatz, M. The Alzheimer's Disease Knowledge Scale: development and psychometric properties. Gerontologist 2009 Mar, 49(2), 236-47.

14. O'Connor, M.L.; McFadden, S.H. Development and psychometric validation of the Dementia Attitudes Scale. Int J Alzheimers Dis 2010, 2010. DOI: 10.4061/2010/454218.

15. Leung, A.Y.M.; Leung, S.F.; Ho, G.W.K.; Bressington, D.; Molassiotis, A.; Lam, C.; Ligot, J.; Valdez, L.P.; Lazalita, A.; Chhit, S.; Chou, P.; Valimaki, M. Dementia literacy in Western Pacific Countries: A mixedmethod study. Int J Geriatr Psychiatry 2019, 1-11. doi: 10.1002/gps.5197

16. Food and Health Bureau, Hong Kong SAR government. Mental Health Review Report 2017. Available online:

https://www.fhb.gov.hk/download/press and publications/otherinfo/180500 mhr/e mhr full report.pdf (accessed on 22 Dec 2019).

17. Valle, R.; Yamada, A-M.; Matiella, A.C. Fotonovelas: A health literacy tool for educating Latino older adults about dementia. Clin Gerontol 2006, 30(1), 71-88. doi:10.1300/J018v30n01_06

18. Jackson, C.E.; Snyder, P.J.; Papp, K.V.; Bartkowiak, J. Dementia literacy: Public understanding of known risk factors. Alzhiemers Dement 2009, 5(4), 410-411. https://doi.org/10.1016/j.jalz.2009.04.1002

19. Public housing key to alleviating poverty. Hong Kong Economic Journal. 2015. Available online: http://www.ejinsight.com/20150203-public-housing-key-to-alleviating-poverty/(accessed on 22 Dec 2019). 
20. Flock, R.; Breitung, W.; Lixun, L. Commodity Housing and the Socio-spatial Structure in Guangzhou - A study based on estate-level residential property prices. China Perspectives 2013, 2013/2, 41-51. doi:10.4000/chinaperspectives.6172

21. Levac, J.; O'Sullivan, T. Social Media and Its Use in Health Promotion. Interdiscip J Health Sci 2010, 1(1). DOI: https://doi.org/10.18192/riss-ijhs.v1i1.1534

22. Parveen, S.; Farina, N.; Shafiq, S.; Hughes, L.J.; Griffiths, A.W. What do adolescents perceive to be key features of an effective dementia education and awareness initiative? Dementia (London) 2018. First published online Oct 30, 2018. doi:10.1177/1471301218807559.

23. Lam, N.H.; Woo, B.K. Exploring the role of YouTube in delivering dementia education to older Chinese. Asian J Psychiatr 2018, 31, 25-26. doi:10.1016/j.ajp.2017.12.022

24. Chan, W.S.Y.; Leung, A.Y.M. A study protocol for a pilot randomized controlled trial on using Facebook for continuous professional education on dementia knowledge and care. In Proceedings of the International Alzheimer's Disease Conference 2018, Hong Kong, China, 31 August 2018.

25. Chan, W.S.Y.; Leung, A.Y.M. (Educational Needs of Pharmacists on Dementia Care: Findings from a CrossSectional Study. In the Proceedings of the 4th International Conference on Pharmacy and Pharmaceutical Science, Tokyo, Japan, 28 March 2019.

26. DeCamp, M. Ethical issues when using social media for health outside professional relationships. Int Rev Psychiatry 2015, 27(2), 97-105. doi:10.3109/09540261.2014.1001726.

27. Dua, T.; Seeher, K.M.; Sivananthan, S.; Chowdhary, N.; Pot, A.M.; Saxena, S. World Health Organization's Global Action Plan on the Public Health response to dementia 2017-2025. Alzheimers Dement 2017, 13, 14501451. 